\title{
Cobalt Catalysis Enables Regioselective Ring-opening of Epoxides with Aryl Halides
}

\author{
Aleksandra Potrząsaj, Mateusz Musiejuk, Wojciech Chaładaj, Maciej Giedyk*, Dorota Gryko* \\ Institute of Organic Chemistry Polish Academy of Sciences, Kasprzaka 44/52, 01-224 Warsaw, Poland
}

\begin{abstract}
:
Ring-opening of epoxides furnishing either linear or branched products belongs to the group of classic transformations in organic synthesis. However, the regioselective cross-electrophile coupling of aryl epoxides with aryl halides still represents a key challenge. Herein, we report the vitamin $\mathrm{B}_{12} / \mathrm{Ni}$ dualcatalytic system that allows for the selective synthesis of linear products under blue-light irradiation thus complementing methodologies that give access to branched alcohols. Experimental and theoretical studies corroborate the proposed mechanism involving alkylcobalamin as an intermediate in this reaction.
\end{abstract}

\section{Introduction:}

Driven by high demand for sustainable and efficient reactions, the discovery of selective reactivity patterns remains a key challenge. As epoxides are crucial building blocks in the synthesis of nonsymmetrical alcohols, their regioselective reactions have been intensively studied. ${ }^{1-3}$ In particular, considerable attention has been recently devoted to the utilization of epoxides in cross-electrophile couplings leading, in general, to regioisomeric (linear and branched) products (Scheme 1).$^{4-7}$ It has been shown that the innately electrophilic epoxides can be transformed into radicals and, as such, be involved in a transition-metal-catalytic cycle. ${ }^{7,8}$ Depending on reaction conditions, the initial nucleophilic attack occurs predominantly either at the terminal or internal carbon atom.

In 2014, Weix and co-workers developed a nickel-catalyzed, regiodivergent cross-electrophile coupling of epoxides with various halides and triflates. ${ }^{9}$ For aliphatic epoxides (Scheme 1, upper part), the regioselectivity of the ring-opening step depends on the co-catalyst used. Sodium iodide promotes the formation of a linear product. The nucleophilic attack of iodide anion at the less substituted carbon atom affords iodohydrin which in turn undergoes reduction and Ni-catalyzed coupling with an electrophile. On the other hand, in the presence of a titanocene co-catalyst secondary alkyl radicals are generated facilitating the formation of branched products. ${ }^{10,11}$ Aryl epoxides, however, react predominantly at the benzylic position, regardless of the conditions employed. A similar reactivity pattern has been recently reported by the Doyle group who used organic iodides and the 
$\mathrm{Ti} / \mathrm{Ni} /$ photoredox catalytic system in ring-opening reactions of three major classes of epoxides, namely: aryl, aliphatic, and bicyclic. ${ }^{12}$ By changing a nickel complex, the authors were able to transform aliphatic epoxides into linear products, while aryl epoxides selectively formed branched ones. Despite the enormous importance of these contributions, the synthesis of linear products from aryl epoxides via cross-electrophile coupling still represents an unsolved challenge.

Our recent work on the alkylation of strained molecules showed that cobalt-catalysis opens the path to polarity-reversal strategy for radical couplings. ${ }^{13}$ We questioned whether it would be possible to adapt this methodology to achieve selective reactions of epoxides. Herein, we disclose that the nucleophilicity of $\mathrm{Co}(\mathrm{I})$ species along with sterically restricted side chains allow to generate C-radicals from epoxides in a selective manner and engage them into Ni-catalyzed cross-coupling.

Scheme 1. Regioselective nickel-catalyzed cross-electrophile coupling of epoxides with aryl halides.

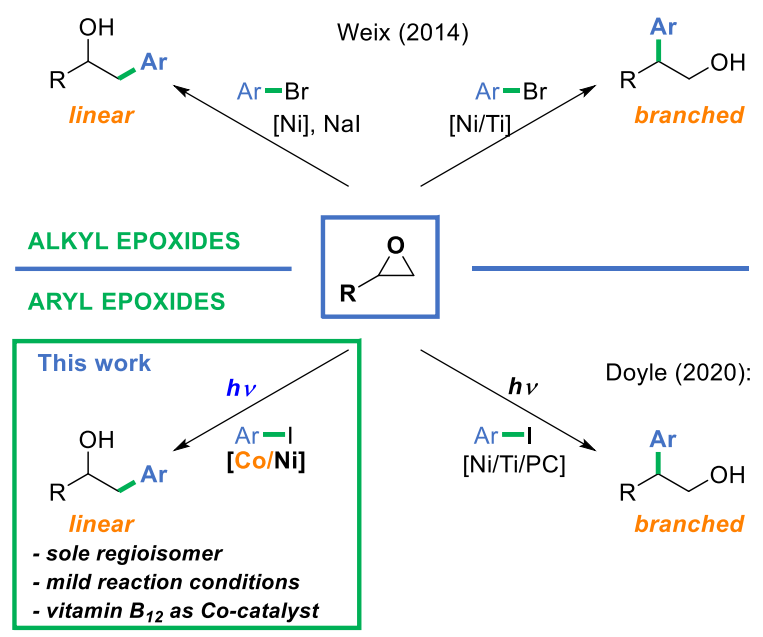

Design of the catalytic system - Vitamin $B_{12}(1)$ is a natural cobalt complex of remarkable stability and high biological importance. ${ }^{14-16}$ Due to the unique ability to form light-sensitive cobalt-carbon bonds, vitamin $\mathrm{B}_{12}(\mathbf{1})$ as well as its hydrophobic and amphiphilic derivatives (Scheme $\left.2 \mathrm{~A}\right)^{17-22}$, have also been adopted for synthetic chemistry and used as a redox mediator for the generation of various radicals. ${ }^{23,24}$ We envisioned that a nucleophilic Co(I) complex, that forms upon the reduction of cobalamin, should open electrophilic epoxides generating alkyl cobalamins (Scheme 2B). Such intermediates, upon light irradiation, undergo homolytic Co-C bond cleavage to give alkyl radicals, which can be engaged in a number of both radical reactions and transition-metal-catalyzed cross-couplings. Importantly, from the viewpoint of regioselective design, a bulky vitamin $B_{12}$ catalyst should attack an epoxide from the less sterically hindered side. This kinetic factor may prevail over the high thermodynamic preference for stabilized benzyl radicals and thus allow the selective formation of primary radicals of type III. 

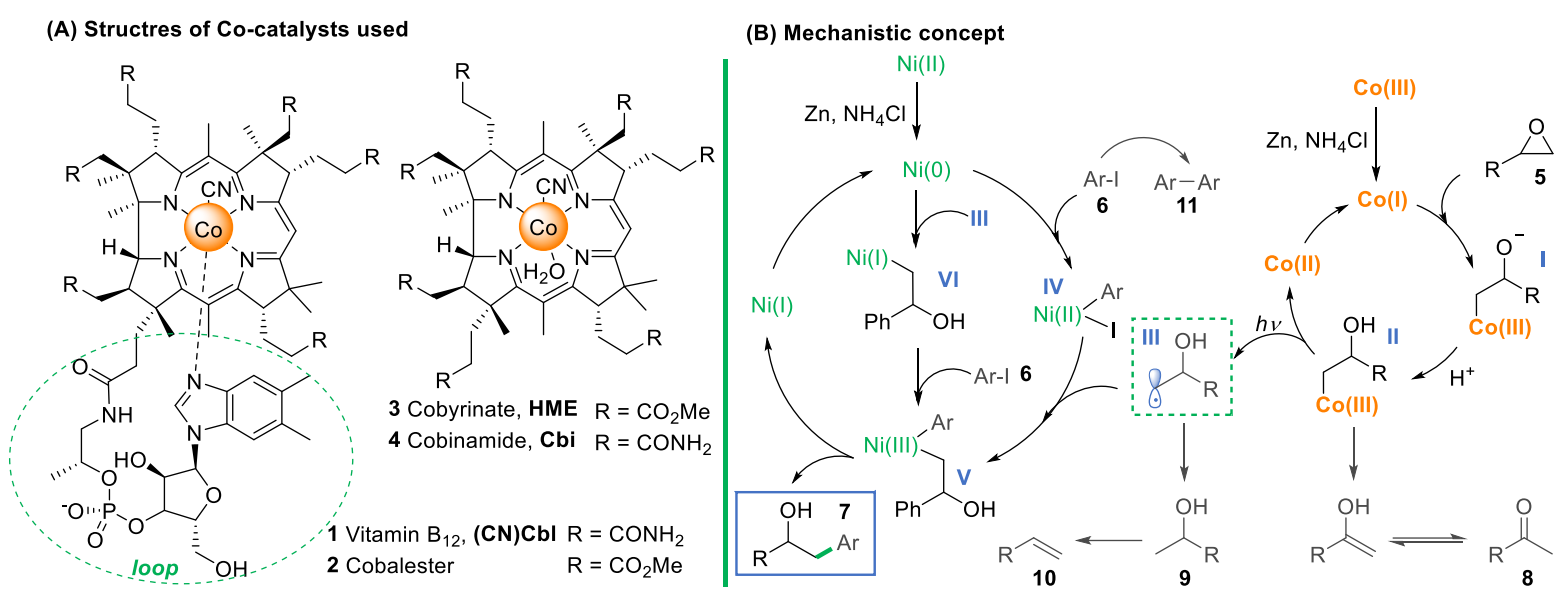

Scheme 2. (A) Structures of Co-catalysts: vitamin B12 and derivatives; (B) Proposed mechanistic concept.

To examine our hypothesis, in the first instance, we theoretically investigated the possible formation of alkyl radicals via a sequence of the epoxide ring-opening with reduced vitamin $\mathrm{B}_{12}$ (Co(I)-complex) followed by homolytic cleavage of the Co-C bond in alkyl cobalamin II. DFT calculations were performed with Gaussian $16 .{ }^{25}$ Geometry optimizations were computed at B3LYP/6-31G(d) level of theory including solvation (acetone) with PCM model. Frequency analysis was performed at the same level to provide correction to thermodynamic functions and confirm the nature of optimized structures (minima and transition states featured zero or one imaginary frequency, respectively). Single point energies were computed at M06/6-311++G(2df,p) level of theory. We performed calculations using truncated structure (Figure 1) of vitamin $\mathrm{B}_{12}(\mathbf{1})$ proposed by Kozlowski et al. ${ }^{26}$

The calculated Gibbs free energy profile for the benchmark reaction of styrene oxide (5a) with the Co-corrin complex is depicted in Scheme 3. In fact, ring-opening of the epoxide with the nucleophilic $\mathrm{Co}(\mathrm{I})$ complex proceeds with $99.1 \mathrm{~kJ} / \mathrm{mol}$ barrier, accessible even under mild conditions. Then the resulting Co(III) complex (I) is protonated providing an intermediate II. As expected for alkyl cobalamins, the Co-C(sp3) bond in II is relatively weak and vulnerable for homolytic cleavage toward alkyl radical III and $\mathrm{Co}(\mathrm{II})$ complex $(\mathrm{G}=80.6 \mathrm{~kJ} / \mathrm{mol})$. In particular, II could undergo $\mathrm{Co}-\mathrm{C}$ photodissociation, presumably through the mechanism proposed by Kozlowski. ${ }^{26}$ Lowest singlet (II-S1) and triplet (II-T1)excited states of intermediate II were found at 1.86 and $1.51 \mathrm{eV}$ (209.9 and 144.6 $\mathrm{kJ} / \mathrm{mol}$ ), respectively (TD M06/6-311++G(2df,p), vertical excitation). Noticeably, thanks to the preference for the nucleophilic attack at the less hindered side of the epoxide, the above-described path should provide access to the less stable 2-hydroxy-2-phenyl ethyl radical (III).

To support theoretical studies, the reductive photochemical ring-opening of styrene oxide (5a) in the presence of hydrophobic vitamin $B_{12}$ derivative - HME (3) was performed (Scheme 3). The selected Co-complex allows convenient monitoring of reactive intermediates by ESI mass spectrometry due to its tendency to undergo facile ionization. Indeed, the formation of an intermediate alkyl-cobalt(III) complex II was observed by HR-MS $\left(m / z=1157.5149[\mathrm{M}+\mathrm{H}]^{+}\right.$, see SI, section 6.2), which is in good 
agreement with previous reports by Scheffold ${ }^{27-31}$ and Rusling ${ }^{32}$, who used vitamin $\mathrm{B}_{12}$ (1) for isomerization of symmetrical epoxides to allyl alcohols.

Figure 1. Calculated Gibbs free energy profile for the reaction of styrene oxide with the Co(I)-corrin complex.

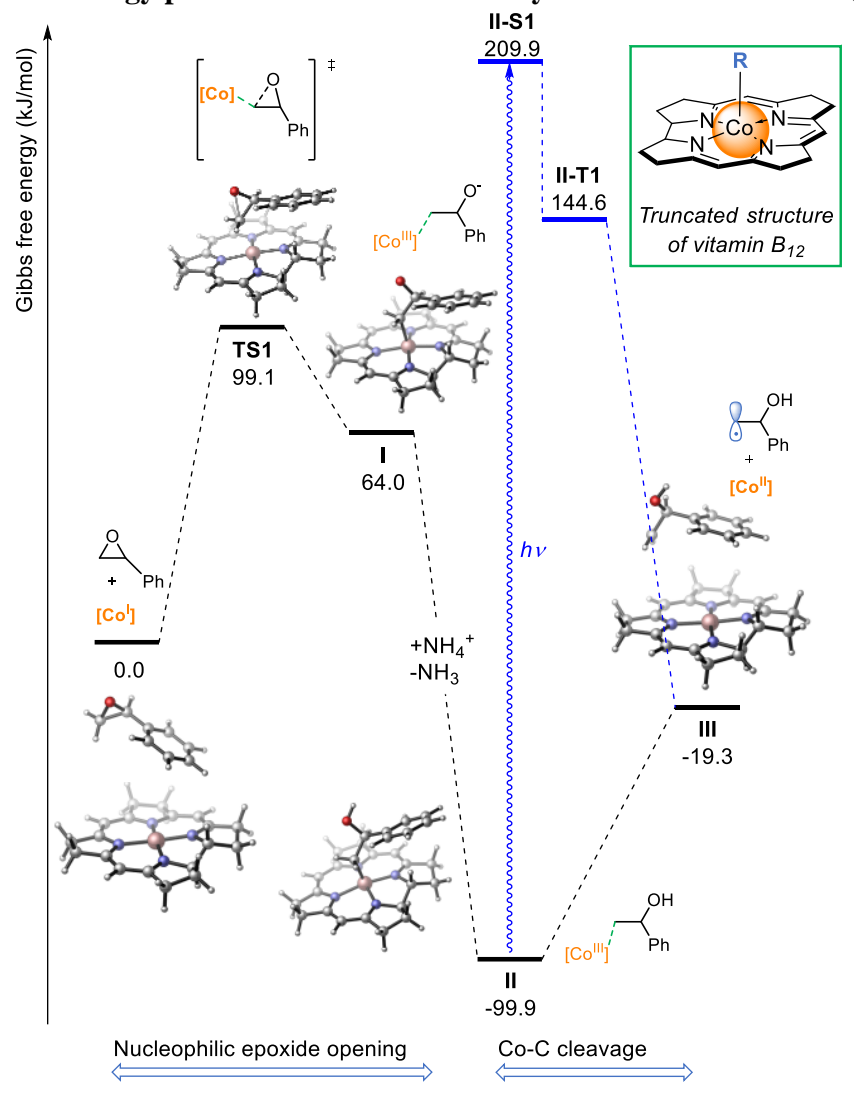

Satisfyingly, alcohol 9a with -OH group at the benzylic position formed just after $30 \mathrm{~min}$. These results corroborate the proposed mechanistic concept in which vitamin $\mathrm{B}_{12}$ opens the aromatic epoxide from the less hindered side at the thermodynamic expense of forming a less stable radical III in the subsequent light-induced cleavage step.

Scheme 3. Vitamin B12-catalyzed ring opening of epoxide 5.

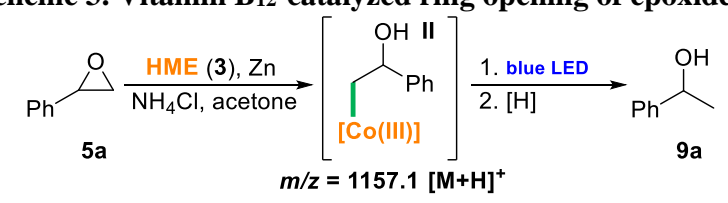

Knowing that $\mathrm{B}_{12}$-catalysis can be merged with metal-catalyzed reactions, ${ }^{13}$ we next evaluated the feasibility of incorporating the generated alkyl radicals in the Ni-catalytic cycle. Adding electrophilic aryl halides should enable cross-electrophile coupling and thus provide a convenient method for the carbon-carbon bond formation. The plausible mechanism for the reaction of epoxides with aryl halides in the presence of the $\mathrm{B}_{12} / \mathrm{Ni}$-catalytic system based on literature reports is outlined in Scheme $2 \mathrm{~B}$. ${ }^{7,33-35}$ The coupling requires the cooperation of both transition metal complexes ( $\mathrm{Co}$ and $\mathrm{Ni}$ ) that are activated by $\mathrm{Zn} / \mathrm{NH}_{4} \mathrm{Cl}^{36,37}$ The oxidative addition of aryl halide to $\mathrm{Ni}(0)$ produces aryl nickel(II) species IV, which undergo subsequent alkylation with radical III and generates intermediate V. Alternatively, the same $\mathrm{Ni}(\mathrm{III})$-species can originate from the interception of alkyl radical III by $\mathrm{Ni}(0)$, preceding the 
oxidative addition, as has been recently proposed by Molander and Kozlowski. ${ }^{38}$ Both these possible pathways are followed by irreversible reductive elimination leading to the regioselective formation of a linear product. Cobalt(II)- and nickel(I)-complexes are regenerated to $\mathrm{Co}(\mathrm{I})$ and $\mathrm{Ni}(0)$ with $\mathrm{Zn}$, thereby closing the cycles.

Styrene oxide (5a), when subjected to the reaction with $p$-iodotoluene (6a) in the presence of HME (3) and $\mathrm{NiCl}_{2}$ (DME), generated desired linear product $7 \mathbf{a a}$ as a single regioisomer in $16 \%$ yield (Scheme 4). The replacement of $\operatorname{HME}(3)$ with native vitamin $B_{12}$ increased the yield up to $41 \%$. Noteworthy, the reaction without any cobalt-complex added was not only lower-yielding but also led to a mixture of two regioisomers with a predominance of the branched product. This result clearly shows the decisive influence of cobalt co-catalysis on the selectivity of this transformation. Control experiments confirmed the dual-catalytic and light-induced nature of the process while the addition of a radical trap (TEMPO) supported its radical character (see SI).

\section{Scheme 4. Proof-of-the concept experiments.}

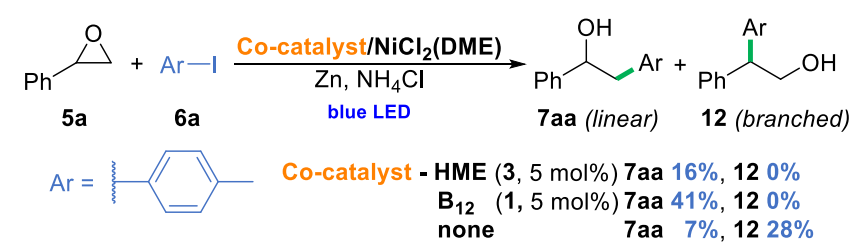

${ }^{a}$ Conditions: epoxide (5a, $0.2 \mathrm{mmol}$ ), aryl halide (6a, 1.5 equiv.), $\mathrm{NiCl}_{2}$ (DME) (20 mol\%), $\mathrm{Zn}$ (3 equiv.), $\mathrm{NH}_{4} \mathrm{Cl}(3 \mathrm{equiv}$.), dtbbpy (40 mol\%), dry NMP ( $c=0.1 \mathrm{M})$, blue LED (single diode, $10 \mathrm{~W}), 30 \mathrm{~min}$.

Optimization - Next, we turned our attention towards the synthetic utility of the developed method. The reaction was optimized with respect to cobalt and nickel catalysts, solvent, ligand, and reducing system providing desired product $7 \mathbf{a a}$ in $60 \%$ yield (Table 1, entry 1). We found that that the addition of water (1.1 equiv.) improves the yield of the reaction, while kinetic studies allowed us to determine the optimal reaction time (30 $\mathrm{min}$ ), for details, see $S I$. The use of hydrophobic HME (3) instead of the parent vitamin $\mathrm{B}_{12}$ had little impact on the optimized model reaction (entry 2), while other cobalt complexes (Co(acac) ${ }_{3}$, $\mathrm{CoCl}_{2}$, cobalt(II)-phthalocyanine) led to a decrease in the yield of alcohol 7aa (entries 3-5). Evaluation of reducing agents ruled out manganese or tetrakis(dimethylamino)-ethylene (TDAE) as an efficient alternative to $\mathrm{Zn} / \mathrm{NH}_{4} \mathrm{Cl}$ system (entry 7). It also allowed establishing the optimal ratio of the two components at 1.5 equiv. : 3 equiv. level. The reaction outcome did not improve in the presence of $\mathrm{NiCl}_{2}$, $\mathrm{Ni}(\mathrm{acac})_{2}$, or $\mathrm{Ni}(\mathrm{OTf})_{2}$ as well as other ligands (entries 8-12). Finally, various solvents were tested (for more details, see SI) but NMP with the addition of water (1.1 equiv.) assured the highest yield (entry $13)$. 
Table 1. Optimization studies of the cross-electrophile ring-opening of epoxides. ${ }^{\text {a }}$

\begin{tabular}{|c|c|c|}
\hline entry & $\begin{array}{l}\text { deviation from } \\
\text { the standard conditions }\end{array}$ & $\begin{array}{c}\text { yield (\%) }^{a} \\
7 \text { aa }\end{array}$ \\
\hline 1 & None & 60 \\
\hline 2 & HME instead of $\mathrm{B}_{12}$ & 57 \\
\hline 3 & $\mathrm{Co}(\mathrm{acac})_{3}$ instead of $\mathrm{B}_{12}$ & 5 \\
\hline 4 & $\mathrm{CoCl}_{2}$ instead of $\mathrm{B}_{12}$ & 7 \\
\hline 5 & $\mathrm{Co}(\mathrm{dmgH})_{2} \mathrm{Cl}(\mathrm{py})$ instead of $\mathrm{B}_{12}$ & 8 \\
\hline $7^{b}$ & Mn instead of $\mathrm{Zn}$ & 30 \\
\hline 8 & $\mathrm{NiCl}_{2}$ instead of $\mathrm{NiCl}_{2}(\mathrm{DME})$ & 36 \\
\hline 9 & $\mathrm{Ni}(\text { acac })_{2}$ instead of $\mathrm{NiCl}_{2}(\mathrm{DME})$ & 33 \\
\hline 10 & $\mathrm{Ni}(\mathrm{OTf})_{2}$ instead of $\mathrm{NiCl}_{2}(\mathrm{DME})$ & 39 \\
\hline 11 & 1,10-phenantroline instead of dtbbpy & 24 \\
\hline 12 & terpyridine instead of dtbbpy & 13 \\
\hline 13 & no water added & 53 \\
\hline
\end{tabular}

${ }^{a}$ Conditions: epoxide (5, $\left.0.2 \mathrm{mmol}\right)$, aryl halide (7, 1.5 equiv.), B12 (5 mol\%), NiCl2(DME) (20 mol\%), Zn (1.5 equiv.), $\mathrm{NH} 4 \mathrm{Cl}$ (3 equiv.), dtbbpy (40 mol\%), H2O (1.1 equiv.), dry NMP $(c=0.1 \mathrm{M})$, time $30 \mathrm{~min}$, blue LED (single diode, $10 \mathrm{~W}$ ) (for more details see SI); ${ }^{b} \mathrm{Mn}$ (1.5 equiv.), TMSCl (0.2 equiv.), dmgH - dimethylglyoxime, dtbbpy - 4,4'-di-tert-butylbipyridine

Detailed analysis of the reaction mixture revealed the formation of by-products aside from desired product 7aa under the optimized conditions (Scheme 2B). Acetophenone (8a a side-product originating from epoxide 5a) formed in 5\% yield presumably via $\beta$-hydride elimination, while styrene (10a) forms in $30 \%$ yield from intermediate alcohol $9 .{ }^{39}$ Finally, the reductive elimination in the nickel cycle may account for the observed small amount of biphenyl $11 .^{40-42}$

Substrate scope - With the optimized conditions in hand, we explored the scope and limitations of the developed method. Monosubstituted aryl epoxides, bearing both electron-withdrawing and electrondonating 5a-f are, in general, well-tolerated and give corresponding products (7aa - fa) in $50-58 \%$ (Scheme 5). However, 2-(4-methoxyphenyl)oxirane (5e) does not afford the desired product as it decomposes rapidly under present conditions. For disubstituted epoxides, the substitution pattern determines their reactivity. 1,1-Disubsituted epoxide $\mathbf{5 f}$ leads to product $\mathbf{7 f a}$ in $44 \%$ yield while $1,2-$ disubstituted epoxide 5g remains unreactive. As far as aryl halides are concerned, under standard conditions, both electron-donating and electron-withdrawing substituents are well tolerated giving desired products 7ab - ao in good to moderate yield (28-63\%). Substitution at the 3- or 4- position of an aryl halide does not affect the reaction. In contrast, the more hindered halide - 2-iodotoluene $(\mathbf{6 c})-$ undergo coupling with styrene oxide (5a) in reduced reaction yield (compare 7aa, 7ab, and 7ac). Though vitamin $\mathrm{B}_{12}$ exhibits exquisite reactivity in dehalogenation reactions, ${ }^{11}$ which often precludes the use of halogenated substrates, in our conditions product 7 ad forms in $44 \%$ yield. Importantly from the standpoint of possible further functionalizations, other functional groups: hydroxyl, carbonyl, protected amine remain unaffected. Moreover, the representative heteroaryl halide, 5-iodo-(4methylphenylsulfonyl)indole (6l) proved to be a viable substrate in the studied reaction without any further optimization needed. 
Scheme 5. Vitamin B12-catalyzed ring-opening cross-electrophile coupling of: (a) aryl epoxides ${ }^{\mathrm{a}}$ and (b) alkyl epoxides ${ }^{\text {b,c. }}$

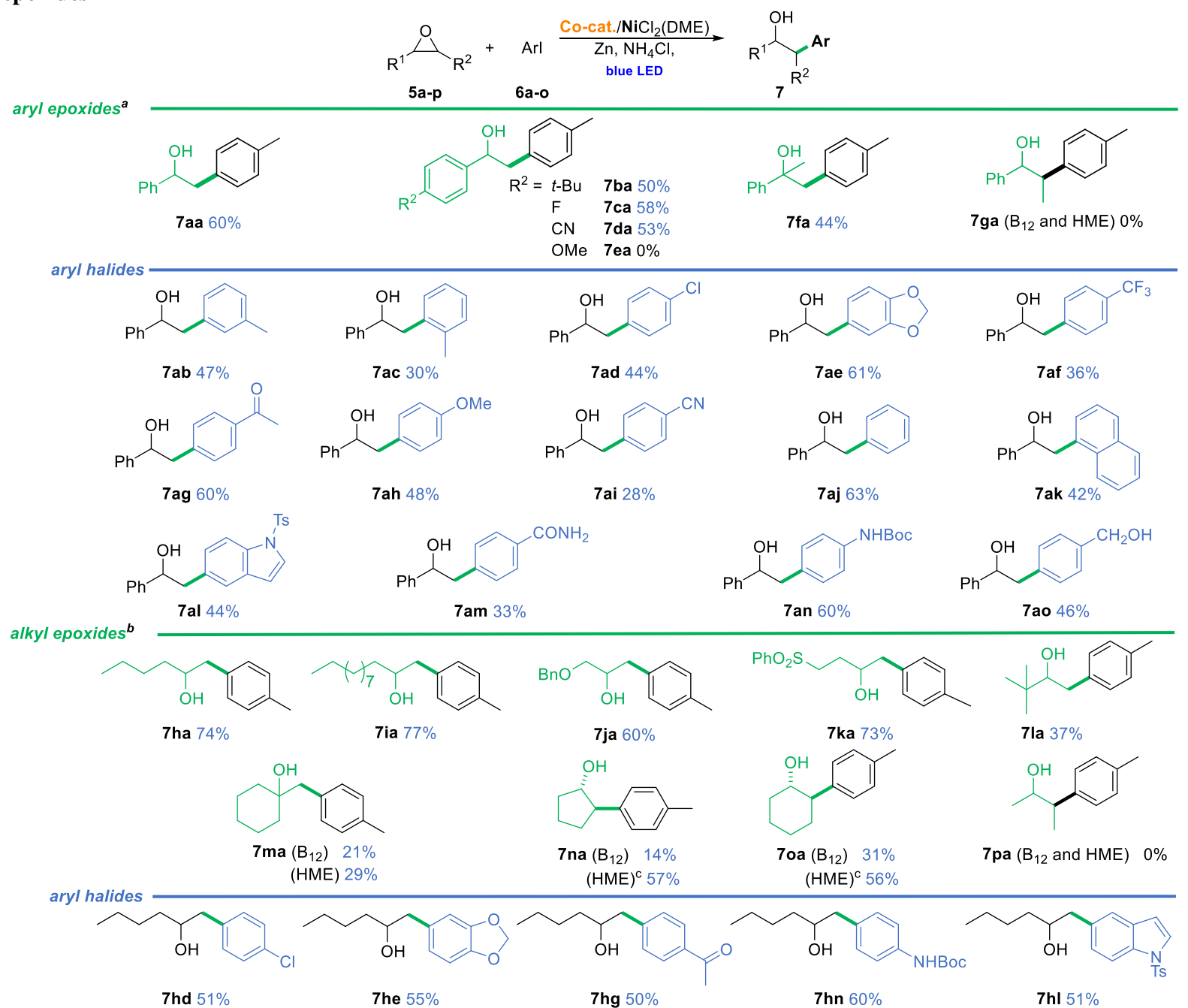

aConditions: epoxide (0.2 mmol), aryl halide (1.5 equiv.), $\mathrm{B}_{12}(5 \mathrm{~mol} \%), \mathrm{NiCl}_{2}$ (DME) $(20 \mathrm{~mol} \%), \mathrm{Zn}\left(1.5\right.$ equiv.), $\mathrm{NH}_{4} \mathrm{Cl}(3$ equiv.), dtbbpy (40 mol\%), $\mathrm{H}_{2} \mathrm{O}$ (1.1 equiv.), dry NMP $(c=0.1 \mathrm{M})$, blue LED (single diode, $10 \mathrm{~W}$ ), 30 min., (for more details see SI); ${ }^{b} 16 \mathrm{~h}$, blue LED (single diode, $3 \mathrm{~W}$ ), ${ }^{\mathrm{c}} \mathrm{HME}(5 \mathrm{~mol} \%)$, acetone $(c=0.1 \mathrm{M})$, blue LED (single diode, $3 \mathrm{~W}$ ), $16 \mathrm{~h}$.

The developed method is also suitable for epoxides with aliphatic substituents (Scheme 6). The chain length does not impact the transformation's outcome; the reaction with 1,2-epoxyhexane (5h) and 1,2epoxydodecane (5i) gives products in respectively $74 \%$ and $77 \%$ yield. We also found that aliphatic epoxide (5j) possessing a protected primary hydroxyl group could be converted into the secondary alcohol $7 \mathbf{j a}$ in $60 \%$ yield. The reaction with 4-(-phenylsulfonyl)-1,2-epoxybutane (5k) gives the corresponding product $7 \mathbf{k a}$ in $73 \%$ yield.

Subsequently, the scope of aryl halides for the reaction with 1,2-epoxyhexane (5h) was explored. Substrates with both types of substituents - electron-rich and electron-deficient - on the aromatic ring afford the corresponding products 7 ha-oa in satisfactory yields. The $N$-Boc-protected amine, alkoxy as well as carbonyl functionalities are well tolerated. The reaction with 1-chloro-4-iodobenzene (6d) leads to anticipated alcohol $\mathbf{7 h d}$ in $51 \%$ yield. Similar to the reaction with aryl epoxides, indole-derived halide $6 \mathbf{l}$ proved also a competent substrate affording 1-(1-tosyl-1H-indol-5-yl)hexan-2-ol (7hl). 
Compared to monosubstituted substrates, bicyclic epoxide $\mathbf{5 0}$ was converted to the desired coupling product 7oa with a significantly lower yield. ${ }^{5}$ Therefore, to gain a better understanding of how the reaction conditions affect the cross-electrophile coupling of disubstituted epoxides with aryl halides, additional experimental and theoretical studies were performed.

The use of hydrophobic analog 3 instead of vitamin $B_{12}$ (1) does not bring any substantial improvement (Table 2, entries 1,2). However, with the simultaneous replacement of NMP with acetone, a twofold increase in the yield of $\mathbf{7 0 a}$ was observed (entry 3). A similar trend was also observed for bicyclic epoxide $\mathbf{5 n}$ and 1-oxaspiro[2.5] octane (5m), which provide considerably higher yields of desired alcohols $7 \mathbf{n a}$ and $7 \mathbf{o a}$ in the presence of $\mathrm{HME} /$ acetone system compared to vitamin $\mathrm{B}_{12} / \mathrm{NMP}$. The main feature by which the studied Co-catalysts differ is the presence/absence of the so-called, 'nucleotide loop' (the axial ligand located at the $\alpha$ face of the corrin ring with 5',6'dimethylbenzimidazol (DMB) moiety) in addition to the replacement of amide into ester groups. Halpern et al. reported that in methyl malonyl-coenzyme A rearrangement switching between base-on and base-off forms of $(\mathrm{CN}) \mathrm{Cbl}$ (1) changes the strength of the $\mathrm{Co}-\mathrm{C}$ bond hence the rate of its homolytic cleavage. ${ }^{43}$ To assess if the presence of this structural element impacts opening of bicyclic epoxides, we used cobalester $\mathbf{2}$ as a Co-complex. This catalyst bears a nucleotide loop in its structure, but unlike parent vitamin $\mathrm{B}_{12}$, it dissolves well in both NMP and acetone allowing for a direct comparison. A decisive solvent's dependence was observed, with acetone assuring a higher yield than NMP (entries 4, 5), which corroborates a sole influence of the reaction medium. Likewise, the reaction catalyzed by cobinamide 4 (amide groups, no nucleotide loop) in NMP gives similar results to reactions catalyzed by other $\mathrm{B}_{12-}$ derivatives in this solvent (entry 6).

Performed kinetic studies contributed to a better understanding of the observed differences. The rate of the bicyclic epoxide (5o) ring-opening was found to vary significantly depending on the conditions applied (Chart 1). 
Table 2. Influence of the Co-complex structure on the opening of bicyclic epoxides. ${ }^{\text {a }}$

\begin{tabular}{|c|c|c|c|}
\hline entry & solvent & catalyst & yield (\%) 7oa \\
\hline 1 & NMP & $\left.\mathrm{CONH}_{2}\right|^{\mathrm{B}_{12}}$ loop & 31 \\
\hline 2 & NMP & $\mathrm{CO}_{2} \mathrm{Me} \mid$ no loop & 26 \\
\hline 3 & acetone & \begin{tabular}{c|c}
\multicolumn{2}{c}{$\mathrm{HME}^{13}$} \\
$\mathbf{C O}_{2} \mathbf{M e} \mid$ no loop
\end{tabular} & 56 \\
\hline 4 & acetone & \begin{tabular}{l}
\multicolumn{2}{c}{ Cobalester ${ }^{18}$} \\
$\mathrm{CO}_{2} \mathrm{Me} \mid$ loop
\end{tabular} & 55 \\
\hline 5 & NMP & \begin{tabular}{l}
\multicolumn{2}{c}{ Cobalester } \\
$\mathrm{CO}_{2} \mathrm{Me} \mid$ loop
\end{tabular} & 32 \\
\hline 6 & NMP & \begin{tabular}{l}
\multicolumn{2}{c}{ Cobinamide ${ }^{44}$} \\
$\mathrm{CONH}_{2} \quad$ no loop
\end{tabular} & 35 \\
\hline
\end{tabular}

aConditions: epoxide (5o, $0.2 \mathrm{mmol}$ ), aryl halide (6a, 1.5 equiv.), Co-catalyst (5 mol\%), $\mathrm{NiCl}_{2}$ (DME) (20 mol\%), Zn (1.5 equiv.), $\mathrm{NH}_{4} \mathrm{Cl}$ (3 equiv.), dtbbpy (40 mol\%), solvent ( $c=0.1 \mathrm{M}$ ), blue LED (single diode, $3 \mathrm{~W}$ ), $16 \mathrm{~h}$.

Chart 1. Kinetic profile of the opening of bicyclic epoxides $(60)(A, C, D)$ and aliphatic epoxide $6 \mathrm{~h}(B)$. a,b
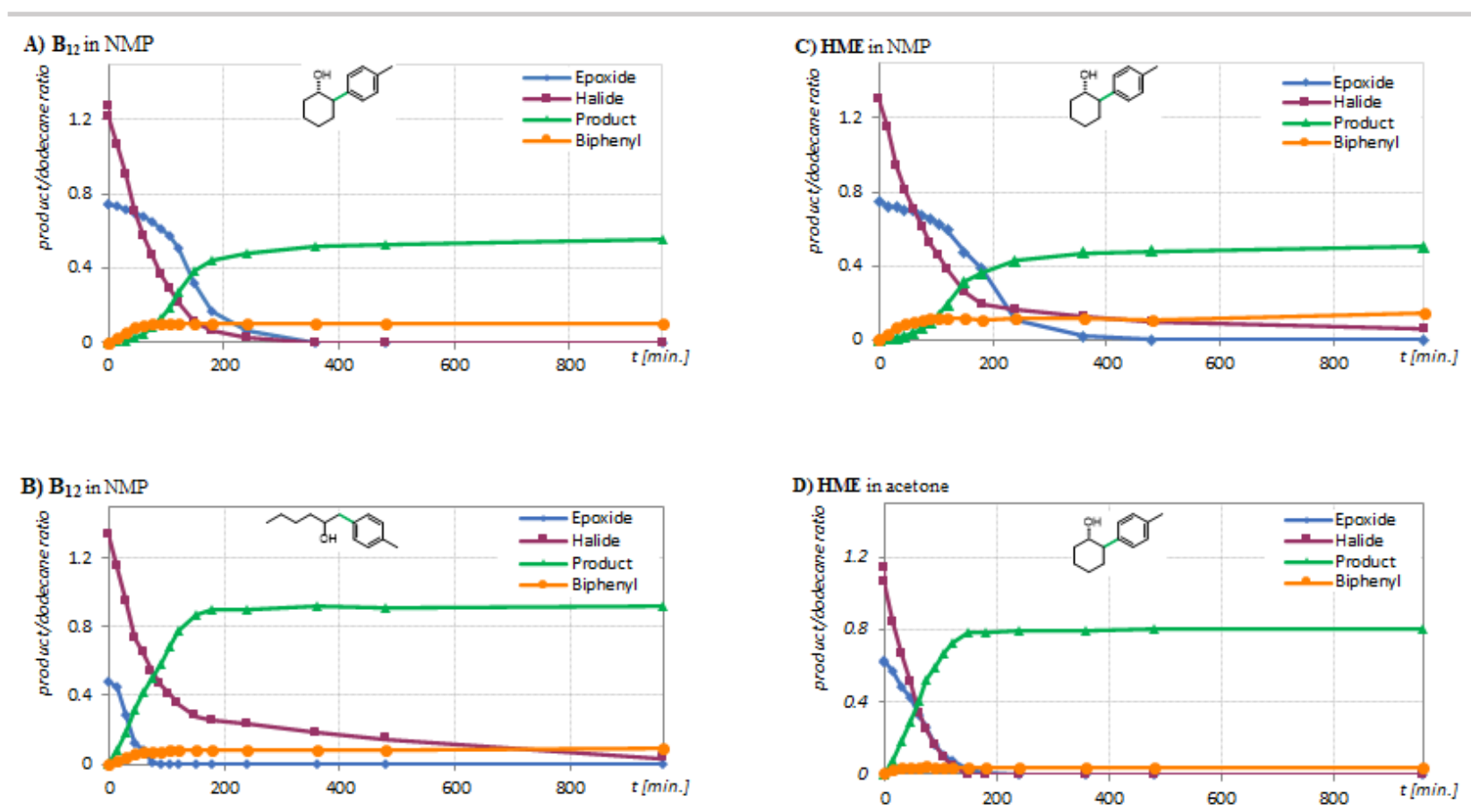

${ }^{a}$ Conditions: epoxide (5, $\left.0.2 \mathrm{mmol}\right)$, aryl halide (6a, 1.5 equiv.), Co-catalyst (5 mol\%), $\mathrm{NiCl}_{2}(\mathrm{DME})$ (20 mol\%), $\mathrm{Zn}$ (1.5 equiv.), $\mathrm{NH}_{4} \mathrm{Cl}$ (3 equiv.), dtbbpy $(40 \mathrm{~mol} \%)$, solvent $(c=0.1 \mathrm{M})$, blue LED (single diode, $\left.3 \mathrm{~W}\right), 16 \mathrm{~h}$. ${ }^{\mathrm{b}}$ measurements at $\mathrm{t}=0 \mathrm{~min}$. refer to concentrations of compounds before mixing two solutions, see SI.

It takes 6 hours to fully convert epoxide $\mathbf{5 0}$ in both vitamin $\mathrm{B}_{12}$ - and HME-catalyzed reactions as long as NMP is used as a solvent (compare fields $\mathbf{A}$ and $\mathbf{C}$ ). On the other hand, the reaction in acetone provides full conversion in less than $3 \mathrm{~h}$ which, presumably, translates to greater availability of alkyl radicals at a particular time (compare fields $\mathbf{C}$ and $\mathbf{D}$ ). 
The reactivity of aryl iodide towards Ni-catalyst is assumed to be at a similar level, regardless of the conditions applied. Therefore, in NMP an insufficient concentration of alkyl radicals derived from bicyclic epoxides may promote Ni-catalyzed homocoupling of aryl iodide (6a), an unproductive pathway, leading to biphenyl (11a) (fields A and C). ${ }^{40,42}$ This side-product is observed only in the presence of the Ni-complex. The higher reactivity of monosubstituted aliphatic epoxide $\mathbf{5 h}$ is reflected by its faster conversion as compared to bicyclic epoxide $\mathbf{5 0}$ (compare fields $\mathbf{A}$ and $\mathbf{B}$ ). In their case, the catalyst and the solvent used does not affect the reaction, yields are almost identical (74\%) in both cases.

The observed reactivity pattern corresponds well with reflected in the calculated barriers for the nucleophilic opening of the epoxides with Co(I)-corrin complex (Figure 2).

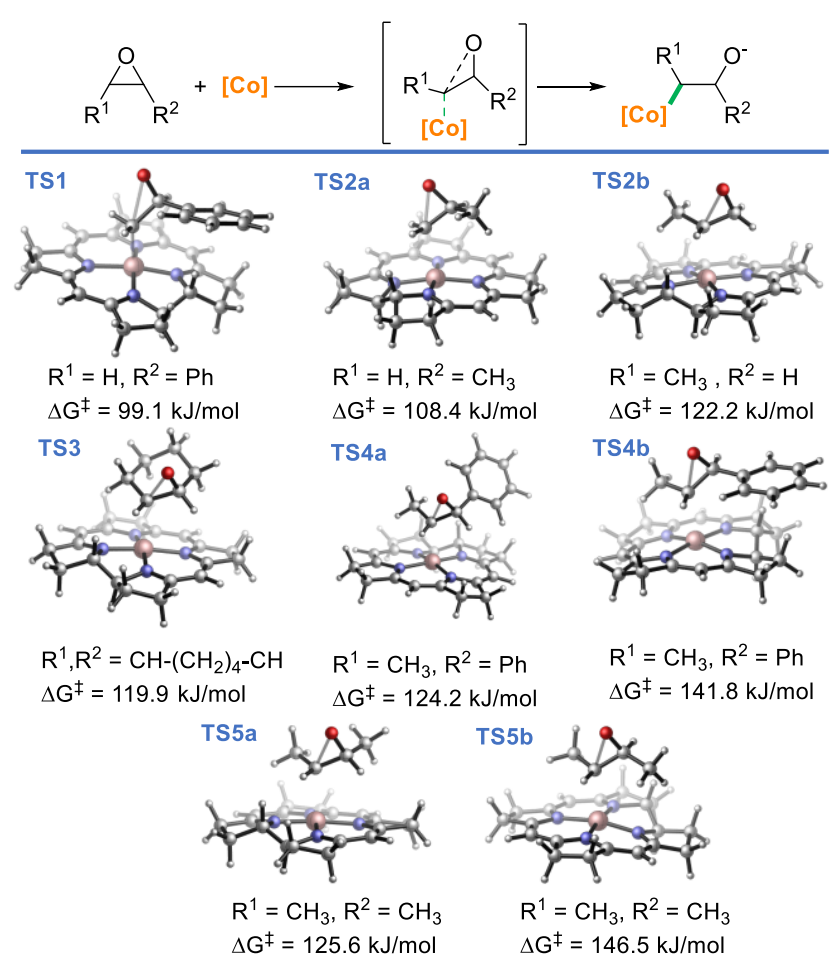

Figure_2. Gibbs free energy barriers for the opening of epoxides with the Co(I)-corrin complex (D) calculated at M06/6$311++\bar{G}(2 d f, p) / / B 3 L Y P / 6-31 G(d)$ level of theory.

In general, the Gibbs free energy of activation for the reaction of alkyl- and aryl monosubstituted epoxides (TS1 and TS2a, 99.1 and $108.4 \mathrm{~kJ} / \mathrm{mol}$ for Me- and Ph- substituted, respectively) is smaller than for more sterically demanding 1,2-disubstituted epoxides (TS3-5, 119.9 - $146.5 \mathrm{~kJ} / \mathrm{mol}$ ). Nevertheless, bicyclic substrates $5 \mathbf{n}, \mathbf{o}$ provide desired products $7 \mathbf{n a}$, oa in good yields while epoxide 5p for which the activation barrier is $\sim 6 \mathrm{~kJ} / \mathrm{mol}$ higher remains unreactive (TS3a versus TS5a) regardless of the cis/trans configuration of the epoxide (TS5a vs. TS5b, $\Delta \mathrm{G}^{\star}=125.6 \mathrm{vs} .146 .5 \mathrm{~kJ} / \mathrm{mol}$ ). Additionally, the observed regioselectivity is well reflected by the energetically favored attack of the $\mathrm{Co}(\mathrm{I})$-corrin on the less hindered side on propylene oxide (a model used for an alkyl epoxide, TS2a vs. TS2b, $\Delta \mathrm{G}^{\ddagger}=108.4$ vs. $122.2 \mathrm{~kJ} / \mathrm{mol}$ ). 


\section{Conclusions}

We have developed a highly regioselective, $\mathrm{Co} / \mathrm{Ni}$-catalyzed ring-opening reaction of epoxides with aryl halides. The scope of our method has been demonstrated in a broad range of aliphatic and aromatic epoxides. Gratifyingly, these include cyclic and disubstituted epoxides even though the Gibbs free energy of activation for their reactions are higher than for alkyl- and aryl monosubstituted substrates. Due to the mild reaction conditions, a wide range of functional groups is well tolerated.

Only the cooperation of vitamin $\mathrm{B}_{12}$ as a Co-catalyst with $\mathrm{Ni}$ catalysis assures high regioselectivity of the cross-electrophile coupling. The crucial ring-opening by the Co(I)-complex occurs from the less hindered side leading to linear products

This new methodology complements the existing approaches providing access to a diverse array of substituted alcohols, which are valuable feedstock chemicals in synthetic and medicinal chemistry. Consequently, it closes the gap in the synthesis of linear and branched alcohols via cross-electrophile coupling, they are now accessible from both alkyl and aryl epoxides.

\section{ASSOCIATED CONTENT}

\section{AUTHOR INFORMATION}

\section{Corresponding Author}

Dorota Gryko - Institute of Organic Chemistry, Polish Academy of Sciences 01-224 Warsaw, Poland

* E-mail: dorota.gryko@icho.edu.pl

Maciej Giedyk - Institute of Organic Chemistry, Polish Academy of Sciences 01-224 Warsaw, Poland

*E-mail: maciej.giedyk@icho.edu.pl

\section{Notes}

The authors declare no competing financial interests.

\section{ACKNOWLEDGMENT}

Financial support for this work was provided by the Foundation for Polish Sciences (FNP TEAM POIR.04.04.00-00-4232/17-00). M.G. gratefully acknowledges funding from the National Science Centre, (SONATA 2018/31/D/ST5/00306). Calculations have been carried out using resources provided by Wroclaw Centre for Networking and Supercomputing (http://wcss.pl), grant No. 518.

\section{REFERENCES}

(1) Pineschi, M. Asymmetric Ring-Opening of Epoxides and Aziridines with Carbon Nucleophiles. European J. Org. Chem. 2006, 2006 (22), 4979-4988. https://doi.org/10.1002/ejoc.200600384.

(2) Huang, C.-Y. (Dennis); Doyle, A. G. The Chemistry of Transition Metals with ThreeMembered Ring Heterocycles. Chem. Rev. 2014, 114 (16), 8153-8198. https://doi.org/10.1021/cr500036t.

(3) Nielsen, L.P.C.; Jacobsen, E. N. Aziridines and Epoxides in Organic Synthesis; Yudin, A. K., Ed.; Wiley, 2006. https://doi.org/10.1002/3527607862. 
(4) Nielsen, D. K.; Doyle, A. G. Nickel-Catalyzed Cross-Coupling of Styrenyl Epoxides with Boronic Acids. Angew. Chemie Int. Ed. 2011, 50 (27), 6056-6059. https://doi.org/10.1002/anie.201101191.

(5) Zhao, Y.; Weix, D. J. Enantioselective Cross-Coupling of Meso -Epoxides with Aryl Halides. J. Am. Chem. Soc. 2015, 137 (9), 3237-3240. https://doi.org/10.1021/jacs.5b01909.

(6) Zhao, Y.; Weix, D. J. Nickel-Catalyzed Regiodivergent Opening of Epoxides with Aryl Halides: Co-Catalysis Controls Regioselectivity. J. Am. Chem. Soc. 2014, 136 (1), 48-51. https://doi.org/10.1021/ja410704d.

(7) Wang, X.; Dai, Y.; Gong, H. Nickel-Catalyzed Reductive Couplings. Top. Curr. Chem. 2016, 374 (4), 43. https://doi.org/10.1007/s41061-016-0042-2.

(8) Wang, C. Electrophilic Ring Opening of Small Heterocycles. Synthesis (Stuttg). 2017, 49 (24), 5307-5319. https://doi.org/10.1055/s-0036-1589102.

(9) Zhao, Y.; Weix, D. J. Nickel-Catalyzed Regiodivergent Opening of Epoxides with Aryl Halides: Co-Catalysis Controls Regioselectivity. J. Am. Chem. Soc. 2014, 136 (1), 48-51. https://doi.org/10.1021/ja410704d.

(10) Gansäuer, A.; Barchuk, A.; Keller, F.; Schmitt, M.; Grimme, S.; Gerenkamp, M.; MückLichtenfeld, C.; Daasbjerg, K.; Svith, H. Mechanism of Titanocene-Mediated Epoxide Opening through Homolytic Substitution. J. Am. Chem. Soc. 2007, 129 (5), 1359-1371. https://doi.org/10.1021/ja067054e.

(11) Gansäuer, A.; Narayan, S. Titanocene-Catalysed Electron Transfer-Mediated Opening of Epoxides. Advanced Synthesis and Catalysis. July 2002, pp 465-475. https://doi.org/10.1002/1615-4169(200207)344:5<465::AID-ADSC465>3.0.CO;2-I.

(12) Parasram, M.; Shields, B. J.; Ahmad, O.; Knauber, T.; Doyle, A. G. Regioselective CrossElectrophile Coupling of Epoxides and (Hetero)Aryl Iodides via Ni/Ti/Photoredox Catalysis. ACS Catal. 2020, 10 (10), 5821-5827. https://doi.org/10.1021/acscatal.0c01199.

(13) Ociepa, M.; Wierzba, A. J.; Turkowska, J.; Gryko, D. Polarity-Reversal Strategy for the Functionalization of Electrophilic Strained Molecules via Light-Driven Cobalt Catalysis. $J$. Am. Chem. Soc. 2020, 142 (11), 5355-5361. https://doi.org/10.1021/jacs.0c00245.

(14) Wierzba, A. J.; Hassan, S.; Gryko, D. Synthetic Approaches toward Vitamin B12 Conjugates. Asian J. Org. Chem. 2019, 8 (1), 6-24. https://doi.org/10.1002/ajoc.201800579.

(15) Brown, K. L. Chemistry and Enzymology of Vitamin B12. Chem. Rev. 2005, 105 (6), 20752149. https://doi.org/10.1021/cr030720z.

(16) Banerjee, R. Chemistry and Biochemistry of B12; Wiley, 1999.

(17) Giedyk, M.; Shimakoshi, H.; Goliszewska, K.; Gryko, D.; Hisaeda, Y. Electrochemistry and Catalytic Properties of Amphiphilic Vitamin B12 Derivatives in Nonaqueous Media. Dalt. Trans. 2016, 45 (20), 8340-8346. https://doi.org/10.1039/c6dt00355a.

(18) Giedyk, M.; Fedosov, S. N.; Gryko, D. An Amphiphilic, Catalytically Active, Vitamin B $<$ inf $>12</$ Inf $>$ Derivative. Chem. Commun. 2014, 50 (36), 4674-4676. https://doi.org/10.1039/c4cc01064g.

(19) Giedyk, M.; Goliszewska, K.; Gryko, D. Vitamin B $<$ inf $>12</$ Inf $>$ Catalysed Reactions. Chem. Soc. Rev. 2015, 44 (11), 3391-3404. https://doi.org/10.1039/c5cs00165j.

(20) Pan, L.; Shimakoshi, H.; Masuko, T.; Hisaeda, Y. Vitamin B12 Model Complex Catalyzed Methyl Transfer Reaction to Alkylthiol under Electrochemical Conditions with Sacrificial Electrode. Dalt. Trans. 2009, No. 44, 9898-9905. https://doi.org/10.1039/b909163g.

(21) Shimakoshi, H.; Li, L.; Nishi, M.; Hisaeda, Y. Photosensitizing Catalysis of the B12 Complex without an Additional Photosensitizer. Chem. Commun. 2011, 47 (39), 10921. https://doi.org/10.1039/c1cc12482j.

(22) Chen, L.; Hisaeda, Y.; Shimakoshi, H. Visible Light-Driven, Room Temperature Heck-Type 
Reaction of Alkyl Halides with Styrene Derivatives Catalyzed by B 12 Complex. Adv. Synth. Catal. 2019, 361 (12), 2877-2884. https://doi.org/10.1002/adsc.201801707.

(23) Pattenden, G. Cobalt-Mediated Radical Reactions in Organic Synthesis. Chem. Soc. Rev. 1988, 17, 361-182. https://doi.org/10.1002/chin.198941359.

(24) Toraya, T. Radical Catalysis in Coenzyme B12-Dependent Isomerization (Eliminating) Reactions. Chem. Rev. 2003, 103 (6), 2095-2127. https://doi.org/10.1021/cr020428b.

(25) M. J. Frisch, G. W. Trucks, H. B. Schlegel, G. E. Scuseria, M. A. Robb, J. R. Cheeseman, G. Scalmani, V. Barone, G. A. Petersson, H. Nakatsuji, X. Li, M. Caricato, A. V. Marenich, J. Bloino, B. G. Janesko, R. Gomperts, B. Mennucci, H. P. Hratchian, J. V., and D. J. F. Gaussian 16, Revision B.01. Wallingford CT 2016.

(26) Kuta, J.; Patchkovskii, S.; Zgierski, M. Z.; Kozlowski, P. M. Performance of DFT in Modeling Electronic and Structural Properties of Cobalamins. J. Comput. Chem. 2006, 27 (12), 14291437. https://doi.org/10.1002/jcc.20454.

(27) Scheffold, R.; Abrecht, S.; Orlinski, R.; Ruf, H.-R.; Stamouli, P.; Tinembart, O.; Walder, L.; Weymuth, C. Vitamin B12-Mediated Electrochemical Reactions in the Synthesis of Natural Products. Pure Appl. Chem. 1987, 59 (3), 363-372. https://doi.org/10.1351/pac198759030363.

(28) Troxler, T.; Scheffold, R. Asymmetric Catalysis by Vitamin B12: The Isomerization of Achiral Cyclopropanes to Optically Active Olefins. Helv. Chim. Acta 1994, 77 (5), 1193-1202. https://doi.org/10.1002/hlca.19940770502.

(29) Su, H.; Walder, L.; Zhang, Z.; Scheffold, R. Asymmetric Catalysis by Vitamin B12. The Isomerization of Achiral Epoxides to Optically Active Allylic Alcohols. Helv. Chim. Acta 1988, 71 (5), 1073-1078. https://doi.org/10.1002/hlca.19880710520.

(30) Bonhôte, P.; Scheffold, R. Asymmetric Catalysis by Vitamin B 12 . The Mechanism of the $\mathrm{Cob}(\mathrm{I})$ Alamin-Catalyzed Isomerization of 1,2-Epoxycyclopentane to ( $\mathrm{R}$ )-Cyclopent-2-Enol. Helv. Chim. Acta 1991, 74 (7), 1425-1444. https://doi.org/10.1002/hlca.19910740706.

(31) Zhang, Z. Da; Scheffold, R. Asymmetric Catalysis by Vitamin B12: The Isomerization of Achiral Aziridines to Optically Active Allylic Amines. Helv. Chim. Acta 1993, 76 (7), 26022615. https://doi.org/10.1002/hlca.19930760719.

(32) Nuthakki, B.; Bobbitt, J. M.; Rusling, J. F. Influence of Microemulsions on Enantioselective Synthesis of (R)-Cyclopent-2-Enol Catalyzed by Vitamin B 12. Langmuir 2006, 22 (12), 5289 5293. https://doi.org/10.1021/la0600191.

(33) Tasker, S. Z.; Standley, E. A.; Jamison, T. F. Recent Advances in Homogeneous Nickel Catalysis. Nature 2014, 509 (7500), 299-309. https://doi.org/10.1038/nature13274.

(34) Ackerman, L. K. G.; Anka-Lufford, L. L.; Naodovic, M.; Weix, D. J. Cobalt Co-Catalysis for Cross-Electrophile Coupling: Diarylmethanes from Benzyl Mesylates and Aryl Halides. Chem. Sci. 2015, 6 (2), 1115-1119. https://doi.org/10.1039/C4SC03106G.

(35) Milligan, J. A.; Phelan, J. P.; Badir, S. O.; Molander, G. A. Alkyl Carbon-Carbon Bond Formation by Nickel/Photoredox Cross-Coupling. Angew. Chemie - Int. Ed. 2019, 58 (19), 6152-6163. https://doi.org/10.1002/anie.201809431.

(36) Komeyama, K.; Michiyuki, T.; Osaka, I. Nickel/Cobalt-Catalyzed C(Sp 3 )-C(Sp 3 ) CrossCoupling of Alkyl Halides with Alkyl Tosylates. ACS Catal. 2019, 9 (10), 9285-9291. https://doi.org/10.1021/acscatal.9b03352.

(37) Komeyama, K.; Ohata, R.; Kiguchi, S.; Osaka, I. Highly Nucleophilic Vitamin B 12 -Assisted Nickel-Catalysed Reductive Coupling of Aryl Halides and Non-Activated Alkyl Tosylates. Chem. Commun. 2017, 53 (48), 6401-6404. https://doi.org/10.1039/C7CC01932G.

(38) Gutierrez, O.; Tellis, J. C.; Primer, D. N.; Molander, G. A.; Kozlowski, M. C. Nickel-Catalyzed Cross-Coupling of Photoredox-Generated Radicals: Uncovering a General Manifold for Stereoconvergence in Nickel-Catalyzed Cross-Couplings. J. Am. Chem. Soc. 2015, 137 (15), 
4896-4899. https://doi.org/10.1021/ja513079r.

(39) Huang, J.-M.; Lin, Z.-Q.; Chen, D.-S. Electrochemically Supported Deoxygenation of Epoxides into Alkenes in Aqueous Solution. Org. Lett. 2012, 14 (1), 22-25. https://doi.org/10.1021/ol2026944.

(40) Manzoor, A.; Wienefeld, P.; Baird, M. C.; Budzelaar, P. H. M. Catalysis of Cross-Coupling and Homocoupling Reactions of Aryl Halides Utilizing Ni(0), Ni(I), and Ni(II) Precursors; $\mathrm{Ni}(0)$ Compounds as the Probable Catalytic Species but Ni(I) Compounds as Intermediates and Products. Organometallics 2017, 36 (18), 3508-3519. https://doi.org/10.1021/acs.organomet.7b00446.

(41) Rahil, R.; Sengmany, S.; Le Gall, E.; Léonel, E. Nickel-Catalyzed Electrochemical Reductive Homocouplings of Aryl and Heteroaryl Halides: A Useful Route to Symmetrical Biaryls. Synthesis (Stuttg). 2018, 50 (01), 146-154. https://doi.org/10.1055/s-0036-1589100.

(42) Iyoda, M.; Otsuka, H.; Sato, K.; Nisato, N.; Oda, M. Homocoupling of Aryl Halides Using Nickel(II) Complex and Zinc in the Presence of Et 4 NI. An Efficient Method for the Synthesis of Biaryls and Bipyridines. Bull. Chem. Soc. Jpn. 1990, 63 (1), 80-87. https://doi.org/10.1246/bcsj.63.80.

(43) Halpern, J. Mechanisms of coenzyme B12-dependent rearrangements. Science, 1985, 227, 869-875. doi:10.1126/science.2857503.

(44) ó Proinsias, K.; Karczewski, M.; Zieleniewska, A.; Gryko, D. Microwave-Assisted Cobinamide Synthesis. J. Org. Chem. 2014, 79 (16), 7752-7757. https://doi.org/10.1021/jo501364b. 